\title{
Phase I/II study of sagopilone (ZK-EPO) plus carboplatin in women with recurrent platinum-sensitive ovarian cancer
}

\section{S McMeekin*, , R Patel ${ }^{2}$, C Verschraegen ${ }^{3}$, P Celano ${ }^{4}$, J Burke II ${ }^{5}$, S Plaxe ${ }^{6}$, P Ghatage ${ }^{7}$, M Giurescu ${ }^{8}$, C Stredder ${ }^{9}, Y$ Wang $^{10}$ and T Schmelter ${ }^{8}$}

'University of Oklahoma Health Sciences Center, Department of Obstetrics and Gynecology, 825 NE IOth Street, Oklahoma City, OK 73 I 04, USA; ${ }^{2}$ Comprehensive Blood and Cancer Center, 6501 Truxtun Avenue, Bakersfield, CA 93309, USA; ${ }^{3}$ University of Vermont, Hematology/Oncology Unit, Given E-21 4 - UVM363, 89 Beaumont Avenue, Burlington, VT 05405, USA; ${ }^{4}$ Greater Baltimore Medical Center, 6569 North Charles Street, Suite 205, Baltimore, MD 21 204, USA; ${ }^{5}$ Mercer University School of Medicine (Savannah), 4700 Waters Avenue, Savannah, GA 3/403, USA; ${ }^{6}$ Rebecca and John Moores UCSD Cancer Center, 3855 Health Sciences Drive \# 0987, La Jolla, CA 92093-0987, USA; '7om Baker Cancer Centre, I 33129 Street NW, Calgary, Alberta T2N 4N2, Canada; ${ }^{8}$ Bayer HealthCare Pharmaceuticals, Müllerstrasse 178, Berlin 13353, Germany; ${ }^{\circ}$ Bayer HealthCare Pharmaceuticals, clo The Courtyard, 30 Worthing Road, Horsham, West Sussex RHI 2 ISL, UK; ${ }^{10}$ Astellas Pharma Global Development, Three Parkway North, Deerfield, IL 600I5-2548, USA

BACKGROUND: Sagopilone is the first fully synthetic epothilone in clinical development and has demonstrated promising preclinical activity. This phase $1 / 1 /$, prospective, open-label trial investigated the efficacy and safety of sagopilone plus carboplatin in patients with recurrent platinum-sensitive ovarian cancer $(\mathrm{OC})$.

METHODS: In phase I (dose-escalation stage), patients with OC recurring at least 6 months after platinum-containing chemotherapy received 3-h infusions of sagopilone (initial dose of $12 \mathrm{mg} \mathrm{m}^{-2}$ ) followed by carboplatin every 3 weeks, for 2-6 treatment courses. Patients enrolled in phase II received 3 -h infusions of $16 \mathrm{mg} \mathrm{m}^{-2}$ sagopilone. Efficacy was assessed using modified Response Evaluation Criteria in Solid Tumors (modRECIST) and Gynecologic Cancer InterGroup CAI 25 criteria. The safety and tolerability of sagopilone were also evaluated.

RESULTS: In all, 45 patients received sagopilone at $12 \mathrm{mg} \mathrm{m}^{-2}$ or $16 \mathrm{mg} \mathrm{m}^{-2}$. There were 29 confirmed tumour responses (2I modRECIST and 8 CA I25) across both treatment groups, indicating that the primary objective of the study was reached. The main adverse events (AEs) reported were peripheral neuropathy (75.6\%), fatigue (7I.1\%) and nausea (64.4\%). Grade $\geqslant 3$ AEs occurred in 35 patients (77.8\%). No deaths related to the study drug were reported.

CONCLUSION: Sagopilone in combination with carboplatin was effective and toxicities were manageable in patients with recurrent platinum-sensitive OC.

British Journal of Cancer (2012) I 06, 70-76. doi:10.1038/bjc.2011.499 www.bjcancer.com

Published online 22 November 201।

(c) 2012 Cancer Research UK

Keywords: sagopilone; carboplatin; ovarian cancer; epothilones

Ovarian cancer (OC) is the leading cause of death in women with gynaecological malignancies in the Western world (Cantù et al, 2002). Epithelial OC accounts for nearly $90 \%$ of OC (Morrison et al, 2007). The incidence of OC increases with age and is most prevalent in the eighth decade of life, with an incidence rate of 57/100 000 (National Comprehensive Cancer Network, 2011).

Early-stage OC (stage I) can often be cured by surgery alone. However, the prognosis for women presenting with an advanced stage (III or IV) is generally poor. Approximately $70 \%$ of patients present with advanced-stage OC (Rochet et al, 2007). Initial treatment for advanced-stage OC involves surgery (debulking) to remove the majority of macroscopic disease followed by platinumbased chemotherapy (Bristow et al, 2002; Galligioni et al, 2006; Ozols, 2006; Pignata et al, 2006; Morrison et al, 2007; National

*Correspondence: Dr S McMeekin; E-mail: scott-mcmeekin@ouhsc.edu Received 25 July 20 II; revised I4 October 201 I; accepted I8 October 201 I; published online 22 November $201 \mathrm{I}$
Comprehensive Cancer Network, 2011). Combination chemotherapy with a taxane such as paclitaxel or docetaxel has demonstrated increased response rates and improvements in progression-free survival (PFS) (McGuire et al, 1996; Piccart et al, 2000; Parmar et al, 2003).

Despite the initial high response rates associated with platinumbased therapies, a significant proportion of patients relapse and require second-line therapy. As the majority of these patients are incurable, the ultimate goal of second-line therapy is to improve their quality and length of life (Ushijima, 2010). Women who relapse $\geqslant 6$ months after initial therapy are considered to have platinum-sensitive disease (National Comprehensive Cancer Network, 2011). The standard of care for platinum-sensitive recurrent disease usually includes combination therapy with a platinumbased compound (carboplatin) and paclitaxel, gemcitabine or liposomal doxorubicin. Platinum-based chemotherapy with paclitaxel has demonstrated improved response rates and survival when compared with conventional platinum-based monotherapy, as shown by the ICON4 trial (Parmar et al, 2003). In a study of 
carboplatin plus gemcitabine $v s$ carboplatin alone for patients with recurrent platinum-sensitive $\mathrm{OC}$, the combined treatment was found to improve PFS (8.6 vs 5.8 months; $P=0.0032$ ) (Pfisterer et al, 2005). The response rate was also improved in the combination group $(47.2 \%$ vs $30.9 \%$; $P=0.0016)$. In the CALYPSO study, combination therapy with carboplatin and liposomal doxorubicin was compared with a regimen of carboplatin and paclitaxel (Pujade-Lauraine et al, 2010). Median PFS was improved in the liposomal doxorubicin group compared with the paclitaxel group (11.3 vs 9.4 months; $P=0.005$ ). Patients who respond to primary treatment but relapse within 6 months are considered to have recurrent platinum-resistant OC. Treatment for these patients includes topotecan, gemcitabine and liposomal doxorubicin, with response rates ranging from 6 to 15\%; however, lengthy remissions are infrequent (Pignata et al, 2006; Rose et al, 2008; Matsuo et al, 2010). There has been increasing evidence to support dose-dense therapy (e.g., extended weekly carboplatin and paclitaxel) for patients with platinum-resistant OC.

Tubulin has been established as a clinically validated target in oncology, and taxanes such as docetaxel and paclitaxel stabilise microtubules and demonstrate significant clinical activity. However, their clinical use is limited by the development of resistance (Fojo and Menefee, 2007). The epothilones are a new class of natural anti-microtubule agents that have a similar mode of action to the taxanes, with potential activity in an expanded spectrum of tumour indications (Cheng et al, 2008; Klar et al, 2008). Sagopilone (ZK-EPO; Bayer HealthCare Pharmaceuticals, Berlin, Germany) is the first fully synthetic epothilone developed for the treatment of solid tumours that has demonstrated antitumour activity in preclinical models (Klar et al, 2006, 2008; Hammer et al, 2007b). This compound exhibits greater levels of efficacy than taxanes, has a fast and efficient cellular uptake with no recognition by efflux mechanisms, and has an improved therapeutic window (Klar et al, 2006, 2008; Hammer et al, 2007a, b; Hoffmann et al, 2008). In phase I studies, sagopilone was well tolerated, with peripheral neuropathy being the most common adverse event (AE) (Arnold et al, 2009; Schmid et al, 2010). Signals of activity were reported in patients with breast cancer, cholangiocellular carcinoma, renal cell carcinoma and other cancer types (Arnold et al, 2009; Schmid et al, 2010). In patients with platinum-resistant OC, sagopilone has demonstrated activity as a single agent, achieving a confirmed response rate of $16 \%$ (Rustin et al, 2011). As sagopilone is administered as a Cremophor-free infusion, pre-medication is not required upon administration of this drug (Arnold et al, 2009).

The recommended dose of sagopilone for phase II studies is $16 \mathrm{mg} \mathrm{m}^{-2}$, with a maximum tolerated dose of $22 \mathrm{mg} \mathrm{m}^{-2}$ (Schmid et al, 2010). The current paper reports data from a phase I/II trial where sagopilone was administered in combination with carboplatin in women with recurrent platinum-sensitive OC.

\section{MATERIALS AND METHODS}

This uncontrolled, open-label, multicentre, phase I/II study (ClinicalTrials. gov identifier: NCT00325351) was conducted at 16 trial sites across Canada and the USA. In phase I of the study, the primary objective was to establish the dose of sagopilone, in combination with carboplatin, to be administered to eligible patients (Figure 1). In phase II of the study, the primary objective aimed to determine the efficacy of sagopilone in combination with carboplatin in women with recurrent platinum-sensitive OC. Secondary objectives were to assess the safety and tolerability of sagopilone in combination with carboplatin in these patients.

In phase $\mathrm{I}$, patients received an initial dose of $12 \mathrm{mg} \mathrm{m}^{-2}$ sagopilone as a 3-h intravenous infusion, followed by a carboplatin infusion (area under the curve 5, calculated using the Calvert formula) every 21 days. Depending on the safety and tolerability

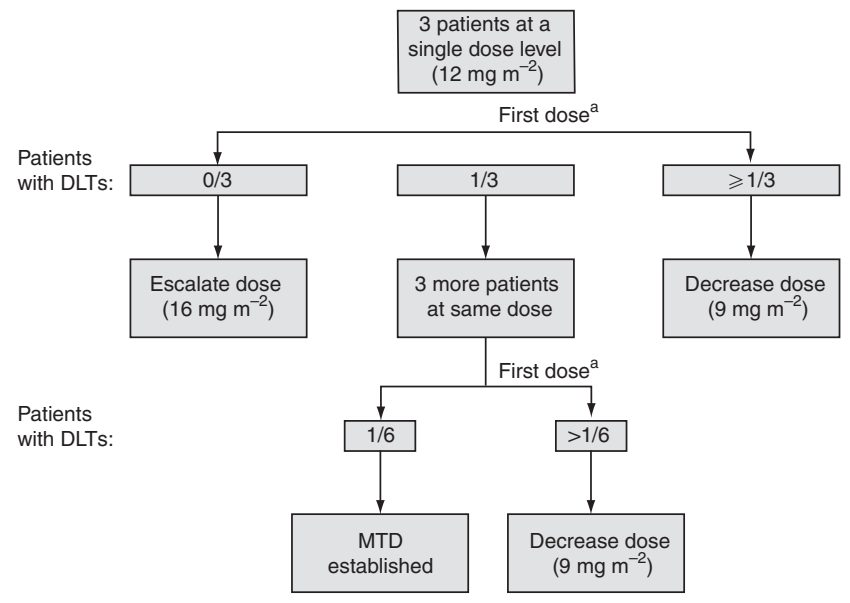

Figure I Dose-escalation flow chart. Abbreviations: DTL, dose-limiting


additional courses at the dose level at which they began treatment.

observed after the initial sagopilone dose, the next dose level was planned to be either 9 or $16 \mathrm{mg} \mathrm{m}^{-2}$.

All patients involved in the study were to receive 2-6 treatment courses of the study drug. Individuals who were observed to benefit from the treatment received additional courses of sagopilone in combination with carboplatin at the dose at which they started treatment.

The phase II part of the study followed a Simon's two-stage design (Simon, 1989): 15 patients were initially treated (step 1), and if there were $\geqslant 6$ responders in these first 15 patients, a further 17 patients were recruited (step 2). Sagopilone was considered effective if $\geqslant 13$ patients of the first 32 evaluable patients responded to the treatment, concluding that the true probability of response was $>30 \%$. Results data from evaluable patients who had received $16 \mathrm{mg} \mathrm{m}^{-2}$ sagopilone in phase I of the study were used for the evaluation of phase II, who were considered as the first patients for step 1 .

The study included females aged $\geqslant 18$ years with histologically proven epithelial OC, peritoneal cavity cancer or fallopian tube cancer. All patients had disease progression or recurrence following a progression-free and platinum-free interval of at least 6 months after completing first-line platinum-based chemotherapy. All patients had a World Health Organization performance status of 0 or 1 and must not have received prior radiotherapy or immunotherapy within 4 weeks of enrollment or prior chemotherapy within 24 weeks of enrollment. All patients must have had adequate recovery (excluding alopecia) from previous surgeries, radiation and chemotherapy, and have adequate function of major organs and systems. Exclusion criteria included patients who had received prior treatment with epothilones, $>1$ previous platinum-based line of chemotherapy, previous radiation to the whole pelvis and symptomatic brain metastases requiring whole-brain radiation.

The study followed the Declaration of Helsinki and conformed to Good Clinical Practice guidelines. The protocol was approved by independent ethics committees for each study centre. Written, informed consent was obtained from each patient before entry into the study.

\section{Assessments}

The tumour response in patients with measurable disease was assessed by the maximum reduction in target lesions within six cycles of treatment, using a modified version of the Response Evaluation Criteria in Solid Tumors (modRECIST) (modified from 
Therasse et al (2000) to include an additional category termed 'unknown', this being the outcome evaluation when response in either the target or the non-target lesion is unknown and no new lesions have been documented). Responders were defined by a $>30 \%$ reduction in the size of target lesion compared with baseline. All responses were evaluated by either magnetic resonance imaging or computed tomography. In individuals without measurable disease, tumour response was evaluated using CA125 levels according to Gynecologic Cancer InterGroup criteria (Rustin et al, 2004). The maximum reduction in CA125 levels was evaluated within 6 days of treatment and responders were defined by $a \geqslant 50 \%$ reduction in CA125 levels compared with the pretreatment sample. The incidence, nature and severity of AEs and serious AEs (SAEs) were graded using the Common Terminology Criteria for Adverse Events version 3.0 (Trotti et al, 2003). Standard laboratory assessments such as serum chemistry, blood counts and urinalysis were performed locally.

The primary efficacy variable was the number of patients who responded to treatment. Tumour response was established as best overall response, comprising either a partial response (PR) or a complete response (CR) according to modRECIST. In individuals without measurable disease, response was defined as a confirmed $\geqslant 50 \%$ reduction in CA125 levels compared with baseline levels at the start of the treatment. The secondary end points of the study were as follows: duration of response, defined as the time from initial response (where confirmed CR or PR is established) to the time of disease progression; time to disease progression, the time from date of enrollment to study treatment phase to the establishment of objective tumour progression or death from tumour; PFS, the time from the start of treatment to either tumour progression or death; and overall survival, the time from the start of the study until death.

\section{Statistical analysis}

All baseline characteristics, safety variables and demographics were summarised by descriptive statistics and/or frequency tables where appropriate. Efficacy and safety data were analysed from the full analysis set, which included all patients assigned to the study treatment. All time to event variables (i.e., PFS and overall survival) were calculated using Kaplan-Meier estimates and corresponding graphs. The phase II part of the study was planned and evaluated according to a Simon's two-step design to test the null hypothesis that the true probability of response was $\leqslant 30 \%$ with a significance level of $10 \%$ for the one-sided test, which constituted the primary analysis of the phase II part. With a target response rate of $>50 \%$, chosen based on clinical considerations for the target population, the sample sizes led to the power of $80 \%$.

\section{RESULTS}

A total of 45 women (median age 63 years (range 26-78)) enrolled in the study and received at least one treatment course (Table 1). In all, $36(80.0 \%)$ of these patients had measurable disease, and the remaining $9(20.0 \%)$ had non-measurable disease with increased CA125 levels (i.e., twice the upper limit of normal within 3 months and confirmed within 2 weeks before first infusion). The majority of patients $(66.7 \%)$ were stage IIIC on the International Federation of Gynecology and Obstetrics staging system at first diagnosis, with the most frequent type of cancer being epithelial OC $(75.6 \%)$. Every patient had undergone initial surgery or biopsy; 21 patients (46.7\%) had optimal surgery with no macroscopic residual disease thereafter. All patients had received previous chemotherapy for OC and the majority $(95.6 \%)$ had received prior taxane therapy. All patients had been pre-treated with a platinum-based chemotherapy; none had undergone radiotherapy.
Table I Patient characteristics

Number of patients $(\%)(n=45)$

\begin{tabular}{|c|c|}
\hline Age, median (range), years & $63(26-78)$ \\
\hline \multicolumn{2}{|l|}{ FIGO stage at diagnosis } \\
\hline$|C-||| B$ & $12(26.7)$ \\
\hline IIIC & $30(66.7)$ \\
\hline IV & $3(6.7)$ \\
\hline \multicolumn{2}{|l|}{ WHO performance status } \\
\hline Grade 0 & 44 \\
\hline Grade I & । \\
\hline \multicolumn{2}{|l|}{ Type of cancer } \\
\hline Fallopian tube & $3(6.7)$ \\
\hline Peritoneal cavity & $8(17.8)$ \\
\hline Epithelial ovarian & $34(75.6)$ \\
\hline \multicolumn{2}{|l|}{ Histology findings } \\
\hline Serous cells & $28(62.2)$ \\
\hline Adenocarcinoma & $13(28.9)$ \\
\hline Clear cell type & $2(4.4)$ \\
\hline Endometrioid cells & I (2.2) \\
\hline Other & I (2.2) \\
\hline \multicolumn{2}{|l|}{ Histological grade at first diagnosis } \\
\hline 1 & $3(6.7)$ \\
\hline 2 & $9(20.0)$ \\
\hline 3 & $24(53.3)$ \\
\hline Unknown & $9(20.0)$ \\
\hline \multicolumn{2}{|l|}{ Disease status } \\
\hline Measurable disease & $36(80.0)$ \\
\hline $\begin{array}{l}\text { Sum of longest diameters }(\mathrm{mm} \text { ) of target lesions at } \\
\text { screening, median (range) }\end{array}$ & $67.5(19-269)$ \\
\hline Non-measurable disease & $9(20.0)$ \\
\hline CAI25 serum level $\left(\cup \mathrm{ml}^{-1}\right)$, median (range) & $124.9(|7.5-56| .0)$ \\
\hline CAI25 serum level $\left(\cup \mathrm{ml}^{-1}\right)$ in patients with & $167(77-428)$ \\
\hline & \\
\hline \multicolumn{2}{|l|}{ Prior chemotherapy } \\
\hline । & $42(93.3)$ \\
\hline 2 & $3(6.7)$ \\
\hline Prior taxane therapy & $43(95.6)$ \\
\hline \multicolumn{2}{|l|}{ Platinum-free interval, months (\%) } \\
\hline $6-12$ & II (24.4) \\
\hline$>12-24$ & $19(42.2)$ \\
\hline$>24$ & $15(33.3)$ \\
\hline
\end{tabular}

Abbreviations: $\mathrm{FIGO}=$ International Federation of Gynecology and Obstetrics; $\mathrm{WHO}=$ World Health Organization

The first three patients enrolled in the study received $12 \mathrm{mg} \mathrm{m}^{-2}$ sagopilone, none of whom experienced a dose-limiting toxicity. The remaining 42 patients were treated at a dose of $16 \mathrm{mg} \mathrm{m}^{-2}$, according to dose escalation. These 42 patients completed a total of 206 courses (median of five cycles (range $1-12)$ ), whereas the three patients treated at a dose of $12 \mathrm{mg} \mathrm{m}^{-2}$ completed a total of 18 courses (median of six cycles (range 4-8)). Treatment compliance was high, as the mean individual dose of sagopilone during the first six courses was $15.4 \mathrm{mg} \mathrm{m}^{-2}$ in the $16 \mathrm{mg} \mathrm{m}^{-2}$ group and $12.0 \mathrm{mg} \mathrm{m}^{-2}$ in the $12 \mathrm{mg} \mathrm{m}^{-2}$ group.

Dose reductions occurred in 11 patients $(26.2 \%)$ in the $16 \mathrm{mg} \mathrm{m}^{-2}$-treatment group only. Twenty-five patients $(59.5 \%)$ in the $16 \mathrm{mg} \mathrm{m}^{-2}$-treatment group and three patients $(100 \%)$ in the $12 \mathrm{mg} \mathrm{m}^{-2}$-treatment group required $\geqslant 1$ postponement of the treatment. Dose reductions and postponements were necessitated primarily by the occurrence of AEs. From course 2 onwards, 
treatment was allowed to be postponed for up to 2 weeks, but only two such postponements were allowed.

The median duration of treatment was five cycles. Overall, 18 patients $(40.0 \%)$ completed $\geqslant 6$ courses of the study medication. Treatment was discontinued prematurely by 27 patients $(60.0 \%)$ : one patient in the $12 \mathrm{mg} \mathrm{m}^{-2}$ group and 26 in the $16 \mathrm{mg} \mathrm{m}^{-2}$ group. The primary reason for discontinuation was AEs in 23 patients (14 patients experienced neuropathy). Three patients withdrew their consent (one due to AEs) and one patient discontinued the study for other reasons. No deaths related to study medication were reported.

\section{Efficacy}

The primary efficacy end point was analysed using the primary analysis set, which consisted of the first 32 patients enrolled in phase II, all treated with a $16 \mathrm{mg} \mathrm{m}^{-2}$ dose of sagopilone. As nine patients from step 1 were responders, the study could continue to step 2, where 12 responders were seen in 17 patients. This resulted in a total of 21 responders $(65.6 \%)$, which was greater than the 13 responders required to conclude that the true probability of response was $>30 \%$ and that the study was therefore positive.

In patients with measurable disease, the maximum reduction in target lesions within six cycles of treatment is shown for each individual in Figure 2. The maximum reduction in CA125 levels for each individual is shown in Figure 3.

Of the 42 patients treated with $16 \mathrm{mg} \mathrm{m}^{-2}$ sagopilone, 26 responders $(61.9 \%)$ were observed (Table 2$)$. In this group, among the 34 patients with measurable disease, three $(8.8 \%)$ had a CR, 16 (47.1\%) had a PR and 11 (32.4\%) had stable disease. CA125 was the primary efficacy measurement for the remaining patients without measurable disease. Eight patients were evaluated for a CA125 response and seven had a response $(87.5 \%)$.

In the $12 \mathrm{mg} \mathrm{m}^{-2}$ group, all three patients who were treated had a response. Two patients had measurable disease and both had a PR. One patient was evaluable for CA125 assessment and this patient responded.

Due to the low number of events and patients treated in the $12 \mathrm{mg} \mathrm{m}^{-2}$ group, time to event variables were analysed only for patients in the $16 \mathrm{mg} \mathrm{m}^{-2}$ group. The median duration of response in the 26 responders was 264 days (95\% confidence interval 223-585 days). The median time to tumour progression was 307 days $(95 \%$ confidence interval 235-347 days). As no deaths were reported during the study, PFS data were identical to the time to tumour progression data.

\section{Safety}

All patients were evaluated for safety. All patients reported AEs, most of which had resolved or were resolving at the end of the

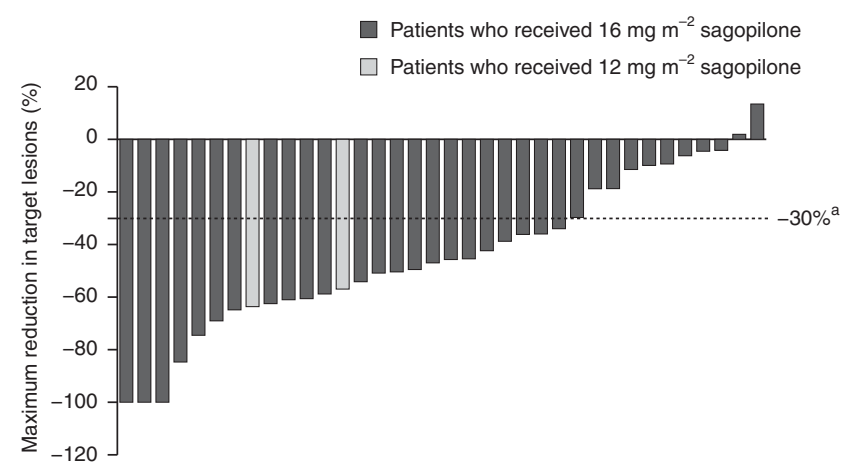

Figure 2 Maximum tumour reduction in target lesions within six cycles of treatment in patients with measurable disease (full analysis set). ${ }^{a}$ Responders were determined by a tumour response rate (or reduction in the size of target lesions) of $-30 \%$.

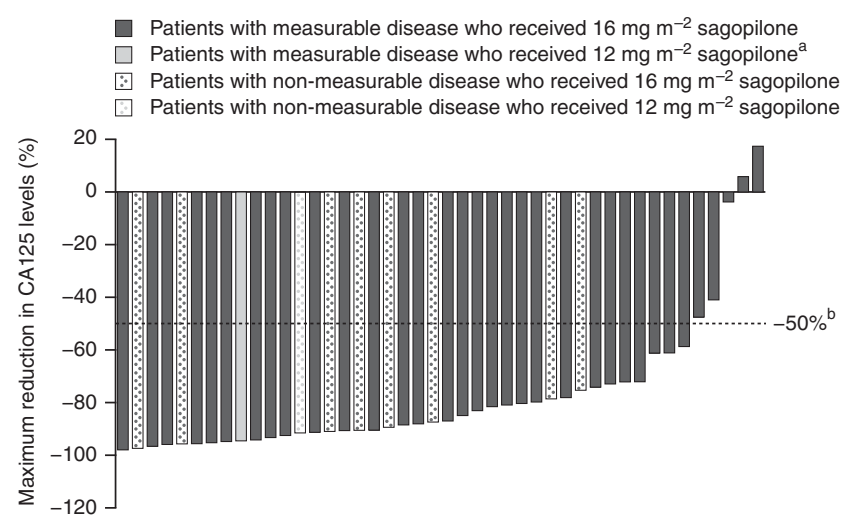

Figure 3 Maximum reduction in CAI25 levels within six cycles of treatment (full analysis set). ${ }^{\mathrm{a}}$ One patient in the $12 \mathrm{mg} \mathrm{m}^{-2}$ treatment group was excluded due to unavailable baseline CAI 25 measurement. ${ }^{\text {b }}$ Response was defined as a $-50 \%$ reduction in CAI 25 levels compared with the pretreatment sample.

Table 2 Best overall tumour response

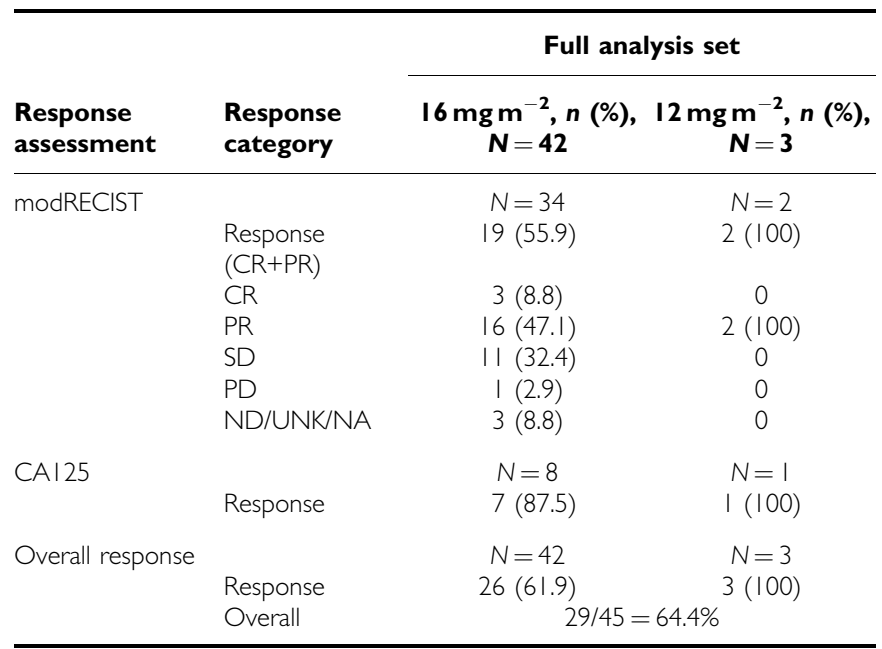

Abbreviations: $C R=$ complete response; modRECIST = modified Response Evaluation Criteria in Solid Tumors; ND/UNK/NA = not done/unknown/not available; $\mathrm{PD}=$ progressive disease; $\mathrm{PR}=$ partial response; $\mathrm{SD}=$ stable disease.

study. The highest incidence was observed for peripheral neuropathy, reported in 34 patients $(75.6 \%)$ (Table 3 ). Other commonly reported AEs included fatigue in 32 patients $(71.1 \%)$, nausea in 29 patients (64.4\%) and neutropaenia in 18 patients $(40.0 \%)$ (Table 3 ). All patients reported at least one AE of grade $\geqslant 2$, with peripheral neuropathy $(57.8 \%)$, fatigue $(44.4 \%)$ and neutropaenia $(40.0 \%)$ being the most commonly experienced. Overall, grade $\geqslant 3$ AEs were reported in 35 patients $(77.8 \%)$ (Table 4). The most commonly reported grade $\geqslant 3$ AEs were neutropaenia $(26.7 \%)$ and peripheral neuropathy (22.2\%) (Table 4). Overall, grade 4 AEs were reported in nine patients (20.0\%): four patients (8.9\%) experienced neutropaenia, two patients $(4.4 \%)$ presented with a decreased neutrophil count, and one case $(2.2 \%)$ each of febrile neutropaenia, thrombocytopaenia and peripheral sensory neuropathy was reported.

A total of 44 patients $(97.8 \%)$ experienced at least one AE that was found to be related to the study drug. The most commonly reported drug-related AEs included peripheral neuropathy (75.6\%), nausea, $(62.2 \%)$, fatigue $(60.0 \%)$ and neutropaenia $(37.8 \%)$.

Nine of the study patients $(20.0 \%)$ experienced a total of 27 SAEs during the trial, all of whom received $16 \mathrm{mg} \mathrm{m}^{-2}$ sagopilone. 
Table 3 Most frequently (> 10\% of all patients) reported adverse events (Common Terminology Criteria for Adverse Events, all grades)

\begin{tabular}{|c|c|c|c|}
\hline & $\begin{array}{c}16 \mathrm{mg} \mathrm{m}^{-2}, \\
N=42, n(\%)\end{array}$ & $\begin{array}{l}12 \mathrm{mg} \mathrm{m}^{-2} \\
N=3, n(\%)\end{array}$ & $\begin{array}{c}\text { Total, } N=45 \text {, } \\
n(\%)\end{array}$ \\
\hline Any event & $42(100)$ & $3(100)$ & $45(100)$ \\
\hline Peripheral neuropathy & $33(78.6)$ & I (33.3) & $34(75.6)$ \\
\hline Fatigue & $30(7 \mid .4)$ & $2(66.7)$ & $32(7 \mid .1)$ \\
\hline Nausea & $28(66.7)$ & I (33.3) & $29(64.4)$ \\
\hline Neutropaenia & $16(38.1)$ & $2(66.7)$ & $18(40.0)$ \\
\hline Diarrhoea & $16(38.1)$ & I (33.3) & $17(37.8)$ \\
\hline Arthralgia & $14(33.3)$ & I (33.3) & $15(33.3)$ \\
\hline Constipation & $13(31.0)$ & $2(66.7)$ & $15(33.3)$ \\
\hline Anaemia & $12(28.6)$ & $2(66.7)$ & $14(31.1)$ \\
\hline Anorexia & $14(33.3)$ & 0 & $14(31.1)$ \\
\hline Headache & $12(28.6)$ & 0 & $12(26.7)$ \\
\hline Vomiting & $12(28.6)$ & 0 & $12(26.7)$ \\
\hline Insomnia & II (26.2) & 0 & II (24.4) \\
\hline Myalgia & $10(23.8)$ & 0 & $10(22.2)$ \\
\hline Pain in extremity & $9(21.4)$ & I (33.3) & $9(20.0)$ \\
\hline Urinary tract infection & $8(19.0)$ & I (33.3) & $9(20.0)$ \\
\hline Dizziness & $7(16.7)$ & I (33.3) & $8(17.8)$ \\
\hline Muscular weakness & $7(16.7)$ & 0 & $7(15.6)$ \\
\hline $\begin{array}{l}\text { Neutrophil count } \\
\text { decreased }\end{array}$ & $7(16.7)$ & 0 & $7(15.6)$ \\
\hline Pyrexia & $6(14.3)$ & I (33.3) & $7(15.6)$ \\
\hline $\begin{array}{l}\text { Upper respiratory tract } \\
\text { infection }\end{array}$ & $5(11.9)$ & I (33.3) & $6(13.3)$ \\
\hline Abdominal pain & $5(11.9)$ & 0 & $5(|| . \mid)$ \\
\hline Dehydration & $5(\mid 1.9)$ & 0 & $5(|| . \mid)$ \\
\hline Musculoskeletal pain & $5(11.9)$ & 0 & $5(|1|)$. \\
\hline Pain & $5(11.9)$ & 0 & $5(|| . \mid)$ \\
\hline Thrombocytopaenia & $3(7.1)$ & $2(66.7)$ & $5(\mid 1.1)$ \\
\hline
\end{tabular}

Table 4 Number of patients with most frequently reported adverse events of Common Terminology Criteria for Adverse Events grade $\geqslant 3^{a}$

\begin{tabular}{|c|c|c|c|}
\hline & $\begin{array}{c}16 \mathrm{mg} \mathrm{m}^{-2} \\
\quad N=42 \\
n(\%)\end{array}$ & $\begin{array}{c}12 \mathrm{mg} \mathrm{m}^{-2} \\
N=3 \\
n(\%)\end{array}$ & $\begin{array}{c}\text { Total, } \\
N=45, \\
n(\%)\end{array}$ \\
\hline Any event & $33(78.6)$ & $2(66.7)$ & $35(77.8)$ \\
\hline Neutropaenia & II (26.2) & I (33.3) & $12(26.7)$ \\
\hline Peripheral neuropathy ${ }^{b}$ & $10(23.8)$ & 0 & $10(22.2)$ \\
\hline Decreased neutrophil count & $4(9.5)$ & 0 & $4(8.9)$ \\
\hline Hypokalemia & $4(9.5)$ & 0 & $4(8.9)$ \\
\hline Arthralgia & $4(9.5)$ & 0 & $4(8.9)$ \\
\hline Anaemia & $3(7.1)$ & 0 & $3(6.7)$ \\
\hline Drug hypersensitivity & $3(7.1)$ & 0 & $3(6.7)$ \\
\hline Catheter-related infection & $3(7.1)$ & 0 & $3(6.7)$ \\
\hline Thrombocytopaenia & 0 & $2(66.6)$ & $2(4.4)$ \\
\hline Fatigue & $2(4.8)$ & 0 & $2(4.4)$ \\
\hline Dyspnoea & $2(4.8)$ & 0 & $2(4.4)$ \\
\hline
\end{tabular}

${ }^{a}$ Adverse events occurred in at least two (4.4\%) patients within the total population. Includes balance disorder, cranial neuropathy, hypoaesthesia, neuralgia, neuropathy peripheral, paraesthesia, peripheral motor neuropathy and peripheral sensory neuropathy.

SAEs occurring in at least two patients included catheter-related infection, anaemia, nausea, vomiting and pyrexia. Drug-related SAEs were experienced by eight patients. All patients who continued with the treatment had recovered by the end of the study.

\section{DISCUSSION}

The study aimed to investigate the efficacy and tolerability of sagopilone in combination with carboplatin in women with recurrent platinum-sensitive OC. The data from the trial showed that the study met its primary end point, with a total of 21 responders $(65.5 \%)$ in the first 32 patients enrolled in the phase II part of the study.

The efficacy findings from this study compare favourably with those reported from other second-line platinum-based combination therapies in patients with OC. Published phase II studies of carboplatin plus paclitaxel or gemcitabine or pegylated liposomal doxorubicin combination regimens for platinum-sensitive recurrent OC have reported response rates in the range of $46-91 \%$ (Rose et al, 1998; Power et al, 2009; Bafaloukos et al, 2010; Ushijima, 2010). A similar range of response rates (47-76\%) was reported in phase III studies of platinum-based combination therapies (Parmar et al, 2003; Pfisterer et al, 2005; Pujade-Lauraine et al, 2010; Ushijima, 2010). The response rate in the present study was $64.4 \%$; however, the population was predominantly patients with modRECIST measurable disease, suggesting that the high response rate is valid. In a single-arm study evaluating a platinum combination therapy in patients with platinum-sensitive recurrent OC, one must be cautious about estimating the effect of the addition of a novel agent, in this case sagopilone, to platinum. In an effort to confirm any significant activity, the threshold established in this study for describing the combination as clinically interesting was 50\%. In the Gynecologic Oncology Group's phase II programme for evaluating platinum combination therapies in platinum-sensitive recurrent OC, it was suggested that if carboplatin combinations result in a response rate of $\leqslant 40 \%$, it is of no clinical interest (Secord et al, 2008) and, conversely, if the true response is $\geqslant 60 \%$, further study is clearly indicated.

The toxicity profile of sagopilone in combination with carboplatin is broadly comparable with that previously observed in patients treated with paclitaxel/platinum-based treatment, in terms of the most commonly reported AEs. In our study, the most frequently reported AEs, in $40-76 \%$ of patients, included neutropaenia, nausea, fatigue and peripheral neuropathy. In the phase III CALYPSO study, anaemia, nausea, sensory neuropathy, neutropaenia, fatigue and alopecia were the most commonly reported AEs in $64-90 \%$ of patients receiving paclitaxel plus carboplatin (Pujade-Lauraine et al, 2010). In the phase III ICON4/ AGO-OVAR-2.2 study, neurological and haematological toxic effects, grades 2-4 nausea and vomiting, and alopecia were experienced by $20-86 \%$ of patients receiving paclitaxel plus a platinum-based chemotherapy (Parmar et al, 2003). Neutropaenia was the most commonly experienced grade $\geqslant 3 \mathrm{AE}(27 \%)$ in our study. The incidence of grade 3 or 4 neutropaenia and haematological toxic effects was $46 \%$ in the CALYPSO study and $29 \%$ in the ICON4/AGO-OVAR-2.2 study, respectively (Parmar et al, 2003; Pujade-Lauraine et al, 2010).

Neurotoxicity events are one of the most clinically relevant events related to sagopilone (Beer et al, 2008; Daud et al, 2009; Schmid et al, 2010; Rustin et al, 2011). In the present study, peripheral neuropathy was the most commonly reported drugrelated $\mathrm{AE}$ experienced by $75.6 \%$ of patients across all grades, the majority of which were reported at grade 1 or 2 . Grade $\geqslant 2$ peripheral neuropathy was reported by $57.8 \%$ of patients in our study. In the ICON4/AGO-OVAR-2.2 study, grades 2-4 neurological toxicities were reported in $20 \%$ of patients receiving a combination of paclitaxel and a platinum-based chemotherapy (Parmar et al, 2003). Similarly, in the CALYPSO study, 27\% of patients receiving paclitaxel plus carboplatin experienced sensory neuropathy of grade $\geqslant 2$ (Pujade-Lauraine et al, 2010).

Sensory neuropathy is a major complication associated with the use of taxanes and epothilones; therefore, the high proportion of patients reporting sensory neuropathy was not unexpected following treatment with sagopilone, especially in a population pre-treated with taxanes. However, the sensory and motor symptoms of neuropathy can be severely disabling and can have a significant impact on a patient's quality of life (De Grandis, 2007). Strategies which reduce the neuropathy rates, including 
improved patient selection, dose scheduling modifications and earlier dose reductions, should be pursued. In addition,

a number of strategies are being studied to overcome sensory neuropathy, including the use of acetyl-L-carnitine (De Grandis, 2007) and oral glutamine (Wang et al, 2004). In a recent phase II study to evaluate the use of acetyl-L-carnitine in the prevention of sagopilone-induced peripheral neuropathy, the incidence of grade 3 or 4 peripheral neuropathy in patients with OC was significantly lower in those receiving acetyl-Lcarnitine (20\%) compared with those receiving placebo (41\%) $(P=0.04)$ (Lhomme et al, 2011).

This study successfully met the primary end point and demonstrates proof of concept for treatment with sagopilone plus carboplatin in women with recurrent platinum-sensitive OC. This combination therapy was feasible in pre-treated patients, with manageable toxicity and activity worthy of further exploration, although vigilance must be exercised in the prevention and management of neuropathy.

\section{REFERENCES}

Arnold D, Voigt W, Kiewe P, Behrmann C, Lindemann S, Reif S, Wiesinger H, Giurescu M, Thiel E, Schmoll H-J (2009) Weekly administration of sagopilone (ZK-EPO), a fully synthetic epothilone, in patients with refractory solid tumours: results of a phase I trial. $\mathrm{Br} \mathrm{J}$ Cancer 101: $1241-1247$

Bafaloukos D, Linardou H, Aravantinos G, Papadimitriou C, Bamias A, Fountzilas G, Kalofonos HP, Kosmidis P, Timotheadou E, Makatsoris T, Samantas E, Briasoulis E, Christodoulou C, Papakostas P, Pectasides D, Dimopoulos AM (2010) A randomized phase II study of carboplatin plus pegylated liposomal doxorubicin versus carboplatin plus paclitaxel in platinum sensitive ovarian cancer patients: a Hellenic Cooperative Oncology Group study. BMC Med 8: 3

Beer T, Smith DC, Hussain A, Alonso M, Neerukonda L, Hauke R, Wang Y, Giurescu M (2008) Phase II study of first-line sagopilone combined with prednisone in patients with metastatic androgen-independent prostate cancer (AIPC). Ann Oncol 19(Suppl 8), Abstract 616P, pviii198

Bristow RE, Tomacruz RS, Armstrong DK, Trimble EL, Montz FJ (2002) Survival effect of maximal cytoreductive surgery for advanced ovarian carcinoma during the platinum era: a meta-analysis. J Clin Oncol 20: $1248-1259$

Cantù MG, Buda A, Parma G, Rossi R, Floriani I, Bonazzi C, Dell'Anna T, Torri V, Colombo N (2002) Randomized controlled trial of single-agent paclitaxel versus cyclophosphamide, doxorubicin, and cisplatin in patients with recurrent ovarian cancer who responded to first-line platinum-based regimens. J Clin Oncol 20: $1232-1237$

Cheng KL, Bradley T, Budman DR (2008) Novel microtubule-targeting agents - the epothilones. Biologics 2: 789-811

Daud A, Weber J, Urbas P, Andrews S, Maker N, Sondak VK, DeConti RC (2009) Phase II trial of sagopilone (ZK-EPO), a novel synthetic epothilone, with significant activity in metastatic melanoma. J Clin Oncol (Meeting Abstr) 27(15 suppl), Abstract 9031, p468s

De Grandis D (2007) Acetyl-L-carnitine for the treatment of chemotherapyinduced peripheral neuropathy: a short review. CNS Drugs 21(Suppl 1): $39-43$

Fojo T, Menefee M (2007) Mechanisms of multidrug resistance: the potential role of microtubule-stabilizing agents. Ann Oncol 18(Suppl 5): v3 - v8

Galligioni E, Arcuri C, Sorio R, Griso C (2006) Gemcitabine and anthracyclines in platinum-resistant ovarian cancer. Ann Oncol 17(Suppl 5): v195-v198

Hammer S, Arnold N, Hilpert F, Bräutigam K, Sommer A, Winsel S, Klar U, Hoffmann J (2007a) Significant antitumour activity of the novel epothilone ZK-EPO against in vitro and in vivo models of ovarian cancer. EJC Suppl 5, Abstract 5009, p313-p314

Hammer S, Lage H, Eschenbrenner J, Winsel S, Mittelstaedt K, Buchmann B, Schwede W, Skuballa W, Klar U, Hoffmann J (2007b) Promising antitumor activity of the novel epothilone ZK-EPO in multidrug-resistant tumor models. AACR Meeting Abstr 2007, Abstract 2294

Hoffmann J, Vitale I, Buchmann B, Galluzzi L, Schwede W, Senovilla L, Skuballa W, Vivet S, Lichtner RB, Vicencio JM, Panaretakis T, Siemeister G, Lage H, Nanty L, Hammer S, Mittelstaedt K, Winsel S, Eschenbrenner

\section{ACKNOWLEDGEMENTS}

We would like to thank all study investigators (listed in the Appendix). We thank Tanya Chaudry and Katherine Wilson at Complete HealthVizion for assistance in the preparation and revision of the draft manuscript, based on detailed discussion and feedback from the authors. Editorial assistance was funded by Bayer HealthCare Pharmaceuticals.

\section{Conflict of interest}

R Patel, C Verschraegen, P Celano, J Burke, S Plaxe, P Ghatage and Y Wang declare no conflict of interest. M Giurescu (Senior Director), C Stredder (Global Study Manager) and T Schmelter (Study Statistician) are all employees of Bayer HealthCare Pharmaceuticals. S McMeekin received funding from Bayer HealthCare Pharmaceuticals for trial enrollment and has participated in advisory boards for Bayer HealthCare Pharmaceuticals.

J, Castedo M, Demarche C, Klar U, Kroemer G (2008) Improved cellular pharmacokinetics and pharmacodynamics underlie the wide anticancer activity of sagopilone. Cancer Res 68: $5301-5308$

Klar U, Buchmann B, Schwede W, Skuballa W, Hoffmann J, Lichtner RB (2006) Total synthesis and antitumor activity of ZK-EPO: the first fully synthetic epothilone in clinical development. Angew Chem Int Ed Engl 45: $7942-7948$

Klar U, Hoffmann J, Giurescu M (2008) Sagopilone (ZK-EPO): from a natural product to a fully synthetic clinical development candidate. Expert Opin Investig Drugs 17: 1735-1748

Lhomme C, Berton-Rigaud D, Joly F, Baurain J, Rolland F, Stenzl A, Schmelter T, Campone M (2011) Results from a randomized phase II study to evaluate the safety and efficacy of acetyl-L-carnitine in the prevention of sagopilone-induced peripheral neuropathy (REASON). J Clin Oncol (Meeting Abstr) 29, Abstract 9116, p578s

Matsuo K, Lin YG, Roman LD, Sood AK (2010) Overcoming platinum resistance in ovarian carcinoma. Expert Opin Investig Drugs 19: $1339-1354$

McGuire WP, Hoskins WJ, Brady MF, Kucera PR, Partridge EE, Look KY, Clarke-Pearson DL, Davidson M (1996) Cyclophosphamide and cisplatin compared with paclitaxel and cisplatin in patients with stage III and stage IV ovarian cancer. $N$ Engl J Med 334: $1-6$

Morrison J, Swanton A, Collins S, Kehoe S (2007) Chemotherapy versus surgery for initial treatment in advanced ovarian epithelial cancer. Cochrane Database Syst Rev CD005343, doi:10.1002/14651858. CD005343.pub2

National Comprehensive Cancer Network (2011) NCCN Clinical Practice Guidelines in Oncology (Ovarian Cancer). Available at: http:// www.nccn.org/professionals/physician_gls/f_guidelines.asp

Ozols RF (2006) Challenges for chemotherapy in ovarian cancer. Ann Oncol 17(Suppl 5): v181 - v187

Parmar MK, Ledermann JA, Colombo N, du Bois A, Delaloye JF, Kristensen GB, Wheeler S, Swart AM, Qian W, Torri V, Floriani I, Jayson G, Lamont A, Tropé C (2003) Paclitaxel plus platinum-based chemotherapy versus conventional platinum-based chemotherapy in women with relapsed ovarian cancer: the ICON4/AGO-OVAR-2.2 trial. Lancet 361: 2099-2106

Pfisterer J, Vergote I, du Bois A, Eisenhauer E (2005) Combination therapy with gemcitabine and carboplatin in recurrent ovarian cancer. Int $J$ Gynecol Cancer 15(Suppl 1): 36-41

Piccart MJ, Bertelsen K, James K, Cassidy J, Mangioni C, Simonsen E, Stuart G, Kaye S, Vergote I, Blom R, Grimshaw R, Atkinson RJ, Swenerton KD, Trope C, Nardi M, Kaern J, Tumolo S, Timmers P, Roy JA, Lhoas F, Lindvall B, Bacon M, Birt A, Andersen JE, Zee B, Paul J, Baron B, Pecorelli S (2000) Randomized intergroup trial of cisplatin-paclitaxel versus cisplatin-cyclophosphamide in women with advanced epithelial ovarian cancer: three-year results. J Natl Cancer Inst 92: 699-708

Pignata S, Pisano C, Di Maio M, Iodice F, Casella G, Laurelli G, Greggi S, Iaffaioli RV (2006) Medical treatment of resistant or recurrent epithelial ovarian cancer. Ann Oncol 17(Suppl 7): vii49-vii50

Power P, Stuart G, Oza A, Provencher D, Bentley JR, Miller Jr WH, Pouliot JF (2009) Efficacy of pegylated liposomal doxorubicin (PLD) plus 
carboplatin in ovarian cancer patients who recur within six to twelve months: a phase II study. Gynecol Oncol 114: 410-414

Pujade-Lauraine E, Wagner U, Aavall-Lundqvist E, Gebski V, Heywood M, Vasey PA, Volgger B, Vergote I, Pignata S, Ferrero A, Sehouli J, Lortholary A, Kristensen G, Jackisch C, Joly F, Brown C, Le Fur N, du Bois A (2010) Pegylated liposomal doxorubicin and carboplatin compared with paclitaxel and carboplatin for patients with platinumsensitive ovarian cancer in late relapse. J Clin Oncol 28: 3323-3329

Rochet N, Jensen AD, Sterzing F, Munter MW, Eichbaum MH, Schneeweiss A, Sohn C, Debus J, Harms W (2007) Adjuvant whole abdominal intensity modulated radiotherapy (IMRT) for high risk stage FIGO III patients with ovarian cancer (OVAR-IMRT-01) - Pilot trial of a phase I/II study: study protocol. BMC Cancer 7: 227

Rose PG, Fusco N, Fluellen L, Rodriguez M (1998) Second-line therapy with paclitaxel and carboplatin for recurrent disease following first-line therapy with paclitaxel and platinum in ovarian or peritoneal carcinoma. J Clin Oncol 16: $1494-1497$

Rose PG, Smrekar M, Haba P, Fusco N, Rodriguez M (2008) A phase I study of oral topotecan and pegylated liposomal doxorubicin (doxil) in platinumresistant ovarian and peritoneal cancer. Am J Clin Oncol 31: 476-480

Rustin G, Reed N, Jayson GC, Ledermann JA, Adams M, Perren T, Poole C Lind M, Persic M, Essapen S, Gore M, Calvert H, Stredder C, Wagner A, Giurescu M, Kaye S (2011) A phase II trial evaluating two schedules of sagopilone (ZK-EPO), a novel epothilone, in patients with platinumresistant ovarian cancer. Ann Oncol 22(11): 2411-2416

Rustin GJS, Quinn M, Thigpen T, du Bois A, Pujade-Lauraine E, Jakobsen A, Eisenhauer E, Sagae S, Greven K, Vergote I, Cervantes A, Vermorken J
(2004) Re: new guidelines to evaluate the response to treatment in solid tumors (ovarian cancer) [letter]. J Natl Cancer Inst 96: $487-488$

Schmid P, Kiewe P, Possinger K, Korfel A, Lindemann S, Giurescu M, Reif S, Wiesinger H, Thiel E, Kühnhardt D (2010) Phase I study of the novel, fully synthetic epothilone sagopilone (ZK-EPO) in patients with solid tumors. Ann Oncol 21: 633-639

Secord AA, Blessing JA, Armstrong DK, Rodgers WH, Miner Z, Barnes MN, Lewandowski G, Mannel RS (2008) Phase II trial of cetuximab and carboplatin in relapsed platinum-sensitive ovarian cancer and evaluation of epidermal growth factor receptor expression: a Gynecologic Oncology Group study. Gynecol Oncol 108: 493-499

Simon R (1989) Optimal two-stage designs for phase II clinical trials. Control Clin Trials 10: 1-10

Therasse P, Arbuck SG, Eisenhauer EA, Wanders J, Kaplan RS, Rubinstein L, Verweij J, Van Glabbeke M, Van Oosterom AT, Christian MC, Gwyther SG (2000) New guidelines to evaluate the response to treatment in solid tumors. J Natl Cancer Inst 92: 205-216

Trotti A, Colevas AD, Setser A, Rusch V, Jaques D, Budach V, Langer C Murphy B, Cumberlin R, Coleman CN, Rubin P (2003) CTCAE v3.0: development of a comprehensive grading system for the adverse effects of cancer treatment. Semin Radiat Oncol 13: 176-181

Ushijima K (2010) Treatment for recurrent ovarian cancer-at first relapse. J Oncol 2010, Article ID 497429; e-pub ahead of print 24 December 2009

Wang MS, Davis AA, Culver DG, Wang Q, Powers JC, Glass JD (2004) Calpain inhibition protects against Taxol-induced sensory neuropathy. Brain 127: 671-679

\section{Appendix}

The following investigators and institutions also participated in the trial:

Alexander Burnett, University of Arkansas, Fayetteville, AR, USA; Allan Covens, Toronto Sunnybrook Regional Cancer Centre, Toronto, Ontario, Canada; Ana Maria López, Arizona Cancer Center at UMC North, Tucson, AZ, USA; David Martin, Baptist

Hospital, Knoxville, TN, USA; James Mason, Scripps Cancer Center, La Jolla, CA, USA; Michael Method, Northern Indiana Cancer Research Consortium, South Bend, IN, USA; Brigitte Miller, Wake Forest University School of Medicine, Winston-Salem, NC, USA; Carolyn Muller and Teresa Rutledge, University of New Mexico Cancer Center, Albuquerque, NM, USA; Peter Rose, MetroHealth Medical Center, Cleveland, OH, USA; Dennis Schribner, Carilion GYN Oncology Associates, Roanoke, VA, USA.

This work is published under the standard license to publish agreement. After 12 months the work will become freely available and the license terms will switch to a Creative Commons Attribution-NonCommercial-Share Alike 3.0 Unported License. 